\title{
DIREITO DE PROPRIEDADE E REGULAÇÃO AMBIENTAL
}

\author{
PROPERTY LAW AND ENVIRONMENTAL REGULATION
}

Rafael Domingos Faiardo Vanzella “.

Resumo:

$\mathrm{O}$ artigo preocupa-se em analisar, no contexto do Direito brasileiro, um pressuposto da regulação ambiental geralmente apontado pelos Autores estadunidenses: a atribuição de direitos de propriedade sobre os bens ambientais. Essa atribuição tem lugar na medida em que os bens ambientais, a partir de um marco de regulação ambiental, deixam de ser tratados como res nullius para que sua utilização seja regulada consoante uma tipologia assentada sobre a dicotomia propriedade pública versus propriedade privada. Fssa tipologia tem várias especificidades no ordenamento juridico brasileiro, e sua construção comparativa revela a inexistência, em nosso direito positivo, de um modelo de propriedade privada comum que não exerça a força tendencionalmente centrífuga da pluralidade de proprietários apresentada pela disciplina do condomínio tradicional. Paradoxalmente aquele modelo seria, conforme sugerem as experiências de utilização humana sustentável dos bens ambientais, o mais indicado para promover uma regulação ambiental ecocêntrica e, por conseqüência, o mais próximo do programa constitucional de regulação ambiental.

Palavras-chave: Legislaçăo ambiental. Direito positivo.

Abstract:

The article aims at analyzing, within the contexı of Brazilian law, a premise of environmental regulation often held by US specialists: the assignment of property rights on environmental goods. From an environmental regulatory perspective, such assignment takes place when environmental goods, instead of being considered res nullius, become the object of a typology constructed from the dichotomy opposing public property versus private property. This typology has many particular characteristics in Brazilian law, whose comparative structure reveals that our law system still lacks a model of common property right capable of escaping the centralizing power of traditional notions of joint ownership. Nonetheless, such a model would be particularly suited to promote an ecocentric environmental regulation as it is suggested by the experiences of human sustainable use of environmental goods - apart from being the most consistunt with Brazilian's constitutional principles on environmental regulation.

Keywords: Enviromental regulation. Positive law.

Artigo originalmente apresentado como trabalho final da disciplina "Teoria da regulação e direito da concorrência", oferecida no primeiro semestre de 2005 pelos Professores Titulares Calixto Salomão Filho e Fábio Nusdeo no curso de pós-graduaçào em sentido estrito da Faculdade de Direito da Universidade de São Paulo. tendo sido avaliado com conceito "A"

. Doutorando em Direito Civil na Faculdade de Direito da I'niversidade de São Paulo. sob a orientação do Professor Doutor Alcides Tomaselli Júnior. 
1. Apresentação do problema

O objetivo deste trabalho é estabelecer relações entre a regulação ambiental, isto é, o conjunto de normas juridicas protetivas de bens ambientais, e o direito de propriedade, a fim de identificar experiências nacionais e estrangeiras e, a partir delas, esboçar um modelo de marco regulatório para a proteção da natureza e a promoção do equilíbrio ecológico no Brasil que tenha por base o direito de propriedade.

Antes de adentrar no cerne das investigações desse trabalho, julgou-se necessário estabelecer algumas premissas na introdução, esclarecendo conceitos e elaborando uma crítica à teoria da regulação com base em textos de teoria geral do direito e teorias sociais. A introdução auxiliará a realização dos cortes metodológicos indispensáveis para o aprofundamento do estudo.

Nos capítulos posteriores, enfrenta-se o tema, isto é, a relação entre direito de propriedade e regulação econômica, fazendo-se as diferenciações necessárias entre regulação econômica e regulação ambiental cuja convergência, aliás, é pressuposto para o desenvolvimento do presente estudo -, propondo uma tipologia dos direitos de propriedade e finalmente, em cada um dos tipos, apresentando sua relação com a regulação ambiental e as experiências nacionais e estrangeiras a respeito de seus objetivos, sucessos e fracassos.

O problema fundamental é de que a regulação ambiental implica, de algum modo, a atribuição de direito de propriedade sobre os bens ambientais (ar, água, florestas etc.), pública ou privada, individual ou coletiva. Isso porque seu objetivo principal é controlar o uso desses bens, evitando seu sobreuso e abuso. O ordenamento jurídico brasileiro, como a maior parte dos ocidentais, reconhece um instituto jurídico clássico que desempenha essa função: a propriedade.

A hipótese de trabalho é que nem a propriedade pública nem a propriedade privada dos bens ambientais permite resultados desejáveis segundo uma regulação ambiental comprometida com os mandamentos constitucionais. A propriedade comum ou coletiva dos bens ambientais, como a dos índios, dos quilombolas e das comunidades locais é que é o mais bem sucedido dos tipos de propriedade, para fins de proteção ambiental. No entanto, ela não é reconhecida pelo direito posto brasileiro. A regulação ambiental em nosso País deve, assim. resolver esse problema essencial, que é pressuposto de todos os demais, pois é necessário definir a titularidade dos bens ambientais antes de estabelecer deveres e direitos. 
Segundo P. Grossi, o jurista moderno jamais questionou senão mesmo aceitou de modo submisso uma série de certezas axiomáticas, entregando-se cega e gratuitamente a um grande projeto de mistificação, isto é, um processo de absolutização de noções e princípios relativos e discutíveis que força a passagem de um mecanismo de conhecimento para um mecanismo de crença. ${ }^{1}$

Essa advertência deve ser preliminar a qualquer estudo jurídico sobre regulação, como se pretende qualificar, aliás, o presente trabalho. A própria expressão "regulação" deveria ab initio causar perplexidade ao jurista que dela faz uso no contexto da chamada "teoria da regulação" Haveria algum ordenamento jurídico que não seja regulador? $\mathrm{H}$. Kelsen havia resolvido de forma definitiva o problema já na primeira metade do século passado: "Sem dúvida o direito (...) é um ordenamento normativo do comportamento humano, isto é, um sistema de normas que regulam comportamentos humanos" 2 Direito e regulação são termos que caminham juntos: ainda que nem toda regulação seja jurídica, todo direito importa regulação; não há direito que não seja regulador da sociedade.

E esse direito de tal forma impactante no corpo social, como observa $\mathrm{K}$. Polanyi ao traçar as relações entre padrões institucionais e princípios comportamentais, ${ }^{3}$ é característico do século XIX: na medida em que uma economia de mercado só se fez possível em uma sociedade de mercado, foi imprescindível conformá-la para que permitisse ao sistema funcionar de acordo com suas próprias "leis" " Daí restar claro que o próprio mercado é uma estrutura institucional, na qual se destaca o papel do Estado na sua implantação, bem como na sua manutenção e aperfeiçoamento. ${ }^{6}$ realçando a efemeridade - e o erro da crença nas espontaneidades.

No mesmo sentido caminha E. Grau ao reforçar a distinção entre direito pressuposto e direito posto, correlata a uma releitura das noções marxistas.

GROSSI, Paolo. Mitologias jurídicas da modernidade. Tradução Arno Dal Ri Júnior. Mitologie giuridiche della modernità. 200I. Florianópolisl; Fundação Boitcux, 2004. p. 12.

KELSEN. Hans. La dolırina pura del diritto. Tradução Mario G. Losano. Reine Rechtslehre. 1960. Turim: Einaudi, 1990. p. 13, sem grifos no uriginal.

3 POLANYI, K. The great transformation. Nova York: Farrar and Rinehart, 1944. p. 43-55.

4 Id. Ibid., p. 57.

3 Id. Ibid., p. $37-8$.

6 Id. Ibid., p. 66. Complementa o autor: "A intervenção estatal, que havia liberado o comércio dos limitus da cidade privilegiada, era agora chamada a lidar com dois perigos estreitamente ligados. os quais a cidade havia contornado com sucesso, a saber, o monopólio e a competição (...). O rumédio encontrado foi a total regulamentação da vida econòmica, só que agora em escala nacional (...). U que para a mente moderna pode parecer como uma imprudente exclusão da competição, foi. na realidade, um mcio de salvaguardar o funcıonamento dos mercados, naquelas circunstâncias"

7 Id. Ibid., p. 76. 
respectivamente, de infraestrutura e superestrutura: se o mercado é delincado pelo direito pressuposto, isto é, o conjunto de normas jurídicas do modo de produção recriadas pelo direito posto, ${ }^{8}$ isto é o conjunto de normas juridicas positivadas pelo Estado, ${ }^{9}$ é somente esse último o direito posto - que institucionaliza o mercado. Isso porque as relações de intercâmbio que se desenvolvem no mercado demandam a presença do Estado, ainda que em grau mínimo, como elaborador de normas jurídicas que tutelem a propriedade privada, a autonomia contratual e a heterocomposição de interesses. ${ }^{10}$ Razão pela qual um "mercado livre" (= ausência do Estado) não corresponde a nenhuma experiência histórica, senão a um modelo ideal." Suas postulações políticas não passam de um engodo: é em virtude do "capitalismo de compadres" (crony capiralism), de que fala P. Arantes, ${ }^{12}$ permitindo que a casta financista se confunda com o próprio Estado, que se pleiteia o esfacelamento deste último como terceiro-ordenador e como terceiro-árbitro.

Por isso a afirmação de que o direito do século XIX não regulava a atividade econômica é um grande equívoco. A consciência de que as "leis" do mercado -vale dizer, o direito pressuposto nunca se bastaram em si mesmas e, portanto, de que o mercado é impossível sem uma regulação estatal que o proteja é explícita na ideologia das grandes codificações, como conclui P. Grossi: "O Código fala ao coração dos proprietários, é sobretudo a lei tuteladora e tranqüilizadora da classe dos proprietários, de um pequeno mundo dominado pelo "ter" e que sonha em investir as próprias poupanças em aquisições fundiárias (...). É por isso que, ao lado da lei do Estado, única concessão pluralista, mas, ao contrário, bem fechada no interior de um surdo monismo ideológico, é admitida como única lei concorrente o instrumento príncipe da autonomia dos indivíduos, ou seja, o contrato. É por isso que o Código - mais que aos utentes, entendidos sempre como destinatários passivos - fala aos juízes, ou seja, aos efetivos aplicadores em cujas mãos passa a ser entregue a tranquillitas ordinis" 13

Tem-se claro, portanto, que, sob a égide do Estado moderno, o primeiro marco regulatório da atividade econômica correspondia ao Direito Privado do século XIX, o qual consagrava os valores constitucionais da propriedade privada e da autonomia contratual. Tamanha importância do direito privado implicou que toda a Ciência do Dircito, que se produzia naquele século e influenciaria decisivamente o

GRAU, Eros Roberto. O direito posto e o dircito pressuposto. 3. ed. Sào Paulo: Malheiros, 2000. p. 44.

Id. Ibid., p. 51.

Id. Ibid., p. 91.

Id. Ibid., p. 92.

ARANTES. Paulo Eduardu. A viagem redonda do capitalismo de acesso. Opiniāo 58 (2004) - capitalismo e propriedade. p. 42.

13 GROSSI, Paolo. Mitologias juridicas da modernidade. Tradução Amo Dal Ri Júnior. Mitologie giuridiche della modernitá. 2001. Florianópolis: Fundação Boiteux, 2004. p. 130 
século vindouro, nele - Direito Privado - se respaldava. O Direito Público não era nada mais do que um seu apêndice, aplicável negativamente: somente quando o direito privado não bastasse para dirimir os conflitos sociais. deveria o Estado atuar mediante a prática do poder de polícia, até hoje definido pelos administrativistas como fórmula de concerto do exercício das liberdades e da propriedade pelos particulares. ${ }^{14}$

Entrementes o movimento de expansão do direito público que surge já nos últimos anos do século $\mathrm{XIX}^{15}$ vem - equivocadamente, como já mencionado - reservar o vocábulo "regulação" para o segundo marco regulatório da atividade econômica sob a égide do Estado moderno, caracterizado pela ampliação do poder de polícia ${ }^{10} \mathrm{e}$, notadamente, pela prática da teoria do serviço público. ${ }^{17}$ Seu apogeu identifica-se nas proposições keynesianas acerca dos "gargalos" do capitalismo e do papel do Estado no seu controle.

No entanto a - cada vez mais crescente - presença do Estado no domínio econômico, seja diretamente, prestando serviços públicos, seja indiretamente, determinando e controlando a atividade dos particulares, inclusive mediante as agências reguladoras, levou à descrença, e - quase mesmo por um ato de fé - ensejou nova crise do marco regulatório no final dos anos $1970 .{ }^{18}$ Era o início da prática das postulações teóricas da Escola Econômica da Regulação." A expressão "regulação" passava a ser usada com um significado ainda mais restrito - e mais equivocado - referente apenas à retração do Estado do domínio econômico e seu papel meramente reprodutor do funcionamento do mercado, a ser desempenhado somente quando este último apresentasse "falhas"

É por isso que o terceiro marco regulatório se caracteriza por uma percepção negativa da função estatal na economia: o poder de polícia e o serviço público têm seus espaços dramaticamente reduzidos, a fim de prestigiar certos instrumentos também regulatórios, outrora paradigmáticos: a autonomia contratual e a propriedade privada.

MEllo, C. A. Bandeira de. Curso de direito administralivo. 14. ed. São Paulo: Malheiros. 2002. p. 697.

15 Cf. SAVATIER, R. Du droit civil au droit public a travers les personnes. les biens el la responsabilité civile. Paris: LGDJ, 1950. p. 3-13.

16 BREYER, Stephen. Regulation and its reform. Cambridge: Harvard University. 1982. p. 1-4.

17 SALOMÃ̃ FILHO, Calixı. Regulação da atividade econômica-principios é fundamentos jurídicos. São Paulo: Malheiros, 2001. p. 17-21.

18 L. C. Bresser Pereira entende que essa década assinala a decadência da "reforma burocrática", isto é. aquela que assinala precisamente o segundo marco regulatório, e o surgimento da reforma gerencial, modelo dominante nos anos 1980 e 1990, a qual caracteriza o terceiro marco regulatório sob a bandeira do "ajuste estrutural das economia em crise". como a economia brasileira (PEREIRA. Luiz Carlos Bresscr. Reforma do Estado para a cidadania . a reforma gerencial brasileira na perspectiva internacional. São Paulo: 34. 1998. p. 22).

1.. SALOMÄO FILHO,('alixto. op. cit., p. 21-6. 
É exatamente nesse ponto que se situam as postulações da propriedade privada como "alternativa" para a regulação ${ }^{20}$ e é precisamente no âmbito da chamada "regulação ambiental" em que se situam as experiências mais marcantes da relação entre direito de propriedade e regulação. Isso porque os componentes ambientais a proteger como a natureza, a fertilidade do solo, o patrimônio cultural construído, as paisagens são realidades que se materializam em um determinado bem imóvel geralmente atribuído a um titular. Assim esse bem imóvel acaba sendo objeto tanto do direito de propriedade de uma determinada pessoa quanto objeto da intervenção do Estado segundo uma teleologia ambiental. ${ }^{21}$

Ao lado dessa primeira relação entre direito de propriedade e regulação ambiental, há uma outra, consistente na percepção de que os próprios bens ambientais devem ser, em si mesmos, atribuídos a uma pessoa, pública ou privada, para lograr os fins da atividade regulatória. É essa segunda perspectiva que o presente estudo enfocará. É necessário, porém, tecer necessárias críticas a essa noção do direito de propriedade como "alternativa" para a regulação, não sem antes evidenciar o sentido de "regulação ambiental" que aqui está-se a empregar.

Mesmo nos Estados Unidos, onde a expressão "regulação" disseminou-se no discurso jurídico, ${ }^{22}$ têm perdido o sentido tanto a distinção entre instrumentos regulatórios - isto é, a determinação e o controle de padrões ambientais - e instrumentos de Direito Privado e Direito Penal - tais como regras de responsabilidade ${ }^{23}$ quanto a

20 BREYER, Stephen. Regulation and its reform. Cambridge: Harvard University, 1982. p. 171-4.

21 FERNANDEZ, Maria Elizabeth Moreira. Direito ao ambiente e propriedade privada - aproximação ao estudo da estrutura e das conseqüências das "leis-reserva" portadoras de vínculos ambientais. Coimbra: Coimbra, 2001. p. 09.

22 Essa expressão pode parecer acertada no contexto estadunidense, pois regulation significa um fenômeno radicalmente diverso do common law: com o primeiro termo, corrclato ao segundo marco regulatório para seguir a presente exposição. refere-se a um padrão de regulação juridica baseada na edição de normas gerais e abstratas pelo parlamento (slatutc law) ou pelas autoridades administrativas; já o segundo termo relaciona-se a um fenômeno que se estende na história da Inglaterra e dos Estados Unidos, dificilmente situado historicamente, e que consiste em um padrão de regulação baseado em normas especificas e concretas cmanadas da atividade interpretativa dos juizes, das quais, mediante procedimentos indutivos, derivam-se principios gerais a serem aplicados a casos análogos. Ambos os fenômenos, porém, implicam regulação, no sentido que este termo apresenta na nossa lingua e, mais do que isso, na tradição dos ordenamentos juridicos ocidentais modemos.

23 Economistas e juristas, porém, sempre apresentaram divergências quanto ao conceito de regulação ambiental ainda mesmo nesse ponto. Para os primeiros, toda intervenção estatal concernente à proteçào ambiental se qualificaria como regulação, ao passo que para os segundos sempre foi bastante nitida a diferença entre o padrão de regulação da regulation (o pleonasmo é proposital) e o padrão de regulação do common law: ao passo que a regulation se lastrearia nas imposições e proibições administrativas - prática do poder de policia - o common law concentraria os institutos de direito privado, tais como a propriedade, o contrato e a responsabilidade (FAURE, Michacl G. Environmental regulation. 1998. p. 443-520. Disponivel em: <http://encyclo.findlaw.com;2300book.pdf $\therefore$. Acesso em: 14 abr. 2005). 
diferença entre instrumentos jurídicos e instrumentos econômicos de regulação. ${ }^{24}$ Isso porque, especialmente em sede de regulação ambiental, é fundamental que o regulador tenha várias opções para tomar sua decisão e conduzir sua política, inclusive combinando formas do Direito Público e do Direito Privado para lograr seus objetivos. Razão pela qual "regulação ambiental" pode ser definida como o conjunto de normas juridicas protetivas dos bens ambientais (ar puro, água, fertilidade e consistência dos solos, fauna e flora, biodiversidade, ecossistemas), independentemente de tais normas contemplarem formas típicas do Direito Público, tais como determinação e controle de padrões e objetivos e outras imposições e proibições administrativas (exercício do poder de polícia), ou do Direito Privado, tais como responsabilidade, contratos e - o que mais interessa neste estudo - propriedade.

Portanto fica claro, primeiramente, por que não tem nenhum sentido afirmar que o direito de propriedade é uma "alternativa" para a regulação. O direito de propriedade é um padrão de regulação; certo, ele é diferente da chamada "regulação clássica" -- ou segundo marco regulatório, como nos limites desse trabalho preferiu-se denominar - caracterizada pelo controle de monopólios e de preços, pela internalização das externalidades negativas, pela imposição de deveres de transparência e de equilíbrio contratual, entre outros. ${ }^{25}$ Mas, de qualquer forma, o direito de propriedade também implica regulação da atividade econômica. ${ }^{26}$ Isso vale inclusive, insista-se, para o

24 Cf. FAURE, Michael G. Environmental regulation. 1998. p. 443-520. Disponivel em: $<$ http://encyclo.findlaw.com;2300book.pdf $>$. Acesso em: 14 abr. 2005. O Autor anota que tanto os instrumentos juridicos são econômicos, pois geralmente dão incentivos aos agentes para cumprir certos objetivos da política ambiental, quanto os chamados instrumentos econòmicos no âmbito da regulação ambiental são juridicos, pois o sistema de multas administrativas e de direitos de poluição negociáveis dependem de um arcabouço juridico para thes conferir legitimidade e determinar quem deve pagar, qual o tipo de atividade está sujeita à regulação, bem como quanto e quando se deve pagar.

25 BREYER, Stephen. Regulation and its reform. Cambridge: Harvard University, 1982. p. 15-35.

26 É muito importante deixar claro, aqui, que o próprio (BREYER, Stephen. op. cit.), apesar de aplicar a expressão "alternativo" para designar modos substitutivos ou complementares àqueles de regulação clássica (p.156), entende que eles não implicam uma ausència do Estado no dominio econômico, senão graus maiores ou menores de presença do Estado na economia. Assim, tem-se que a estatização é um modo de regulação baseado na máxima presença do Estado no domínio econômico. Logo abaixo, disputa uma faixa de intermediária presença do Estado a regulação clássica de um lado e de outro os modos alternativos de regulação. com exceção da estatização e do dircito concorrencial. S. BRFYER entende que aqueles, com as exceçōes referidas, implicariam uma menor presença do Estado relativamente à regulação clássica, na medida em que são mecanismos menos restritivos para atingir os mesmos fins regulatórios. $\mathrm{Na}$ outra extremidade dessa tipologia estaria o direito concorrencial como modo alternativo de regulação no qual o Estado está minimamente presente, cabcndo-lhe exclusivamente lixar regras juridicas as mais das vezes tão somente ncgativas. Graficamente tem-se a seguinte representação:

Regulação da atividade econômica. Prusença máxima do Lstado no domínio econômico. Estatização. Presença maximalista do Estado no dominio econômico. Regulação "clássica". Concessão de serviços públicos. Controle de preços. Controle de monopólios. Internalização das externalidades. Reequilibrio dos contratantes. Dever de transparência. Presença minimalista do Estado no dominio econômico. Regulação "alternativa". Direito tributário. Direito das obrigações. Propriedade privada. Presença mínima do Estado no domínio econòmico. Dircito concorrencial. 
primeiro marco regulatório sob a égide do Estado moderno, consistente no Direito Privado do século XIX, conforme supramencionado. O que se postula, portanto, ao se sustentar o direito de propriedade como "alternativa" para a regulação, é, em grande parte, um retorno a certos dogmas do direito privado oitocentista, o que deve ser aceito com uma série de ressalvas. ${ }^{27}$

Feitas essas considerações introdutórias e imprescindiveis, é possível adentrar no cerne deste estudo, sem se preocupar com as anfibologias que a noção de regulação traz para o jurista, quem definitivamente não pode perder sua perspectiva crítica no conhecimento da sociedade.

3. Propriedade dos bens ambientais como pressuposto do marco regulatório

\subsection{Regulação econômica e regulação ambiental}

Já foi brevemente mencionado que um dos pressupostos deste trabalho é a convergência entre a regulação econômica e a regulação ambiental. Com efeito, é possível que ambas tenham sentidos divergentes ${ }^{29}$ e até mesmo antagônicos. ${ }^{29}$

Os problemas ambientais tiveram uma primeira acolhida pela teoria da regulação por meio do tema das externalidades: a poluição é um exemplo clássico de externalidade negativa. A produção de bens pode implicar a emissão de gases poluentes, poluição da água, produção de lixo. São efeitos negativos que levaram alguns autores da teoria da regulação à formulação das seguintes perguntas: (i) qual é o nível ótimo de emissões; e (ii) como o Direito pode oferecer incentivos para o alcance desse nível ótimo. ${ }^{30}$

À tradicional resposta da fixação de uma multa geralmente de caráter administrativo aos agentes econômicos poluidores, R. Coase objetou com o fato de que a

27 Aqui fica bastante claro como o movimento de restrição do significado da expressão "regulação" . por si só oca no discurso jurídico - é inversamente proporcional à sua ideologização: a idèia è transmitir que regulaçào se refere a um núcleo minimo e que pode ser superado, fazendo ocultar. assim. a estrutura institucional do mercado e o papel fundamental que o direito - e o Estado - exerce para a economia capitalista.

28 Parece certo que grande parte das diferenças entre ambas as regulações vem du fato. denunciado por $\mathrm{K}$. Polanyi, de que os bens ambientais. que são parte da natureza. têm uma diferença intrinseca para com as mercadorias. conquanto em grande parte o capitalismo tenha cunsistido - e de certa forma ainda cunsiste -. $\mathrm{cm}$ transformar aqueles bens em mercadorias; porém. como a natureza não é um bem produzido para ser negociado no mercado, nào é essencialmente mercadoria, senão mercadoria líctícia (POLANYI, K. The great transformation. Nova York: Farrar and Rinchart, 1944. p. 69-73).

29 Cf. ACUTT, Milinda, ELLIOTT, Caroline. Regulatory conflict? Environmental and economic regulation of electricity generation. 1998. p. 1-24. Disponivel em: $<$ http://papers.ssm.com/sol3/papers.cfm?absatract_id=200572-. Acesso cm: 14 abr. 2005.

30 FAURE, Michael G. Environmental regulation. 1998. p. 443-520. Disponivel em: <http://encyclo.findlaw.com;2300bouk.pdB. Acesso em: 14 abr. 2005. 
poluição é um problema não-somente porque é causada pelas emissões prejudiciais das fábricas, mas também porque há uma vizinhança que se incomoda com as fumaças. ${ }^{31}$ Do ponto de vista da eficiência, se os custos para a instalação de um filtro forem menores do que os custos para recuperar os prejuízos causados pela poluição, haveria uma realocação "natural" no sentido da instalação do filtro. Permaneceria, todavia, uma questão fundamental, de base distributiva: qual dos agentes - a fábrica ou a vítima deve pagar pelo filtro? O ganhador do Prêmio Nobel de Economia, de 1991, sustenta que haveria negociações entre as partes se os custos de negociação (transaction costs) fossem iguais a zero, o que engendraria a solução mais eficiente. O papel da regulação econômica seria, assim, o de reduzir os custos de negociação que existem em uma economia real e equilibrar o poder de barganha das partes. ${ }^{32}$

A regulação ambiental apresenta, contudo, tendência diversa. Quando há um poluidor, a regulação procura atribuir um direito subjetivo a uma pessoa, pública ou privada, que seja lesada pela poluição: trata-se da vítima, o que equivale a dizer que ser vítima significa ter um direito reconhecido e garantido pelo ordenamento jurídico. A internalização de custos da poluição - o conhecido princípio do poluidor-pagador - é regra em sede de regulação ambiental, tendo a eficiência, nesse aspecto, pouca relevância ${ }^{33}$ Esse direito subjetivo da vítima traduz-se, as mais das vezes, em um direito de crédito, o qual pode, em um sentido amplo, ser denominado direito de propriedade, como será visto adiante.

Observa-se, até o momento, que a regulação ambiental e a regulação econômica oferecem respostas diferentes àquela segunda pergunta como o direito pode oferecer incentivos para o alcance do nivel ótimo de emissão de poluição. A regulação ambiental responde sempre com a atribuição de um direito de propriedade: o direito subjetivo ao recebimento da multa, geralmente por parte do Estado, ou o direito subjetivo ao recebimento da indenização, ambos direito de crédito a ser satisfeito pelo poluidor. Veja-se que previamente a esses direitos de crédito já há a atribuição de um outro direito de propriedade, qual seja, o de titularidade sobre um determinado bem ambiental. Há claramente um posicionamento distributivo. A regulação econômica, por sua vez, responde essa mesma pergunta de modo diverso: o problema é eliminar ou diminuir custos de negociação para que os custos sejam realocados pelas forças do próprio mercado, momentaneamente impedidas de lograr seus objetivos em virtude de falhas.

\footnotetext{
3 COASE, Ronald Harry. The firm. the market and the law. Chicago: University of Chicago, 1990. p. 96.

32 FAURE, Michael G. Environmental regulation. 1998. p. 443-520. Disponivel em: $<$ http://encyclo.findlaw.com:2300book.pdf>. Acesso em: 14 abr. 2005.

33 Id. Ibid.
} 
Voltando, agora, à primeira pergunta qual é o nivel ótimo de emissões, vêse que a regulação econômica tende a dar uma resposta com base no critério de custobenefício: o regulador deve comparar o que a sociedade recebe do controle da poluição e da regulação ambiental com o que ela perde tomando bens dos agentes econômicos: ele deve mensurar os valores do que a sociedade ganha (os benefícios) e do que ela perde (os custos), de acordo com as preferências de quem experimenta essas perdas e ganhos. ${ }^{34}$

É evidente que esse tipo de análise se presta a auxiliar, no âmbito de uma intervenção do Estado, a política econômico-ambiental mais eficiente do ponto de vista alocativo. Mas faz tábula rasa de uma questão crucial para a regulação ambiental. concernente à apreciação dos benefícios por uma perspectiva antropocêntrica, focando. por exemplo. simplesmente na redução dos riscos à saúde humana gerados pela poluição, ou por uma perspectiva ecocêntrica, para a qual a qualidade ambiental é um fim em si mesma.

Em matéria de regulação ambiental, essas decisões não podem, em grande parte, ser simplesmente tomadas pelos agentes políticos e econômicos. A Constituição da República tem, em diversas passagens, normas programáticas sobre matéria ambiental. E considerando que a defesa do meio ambiente é princípio da ordem econômica brasileira (art. 170, VI da Constituição), justifica-se o pressuposto da convergência entre regulação econômica e regulação ambiental, assumido visando ao desenvolvimento do presente estudo. Ora, mais do que isso, a Constituição brasileira configura um autêntico Estado de Direito Ambiental. ${ }^{35}$ Isso significa que ao Estado (art. 23, VI e VII; art. 24, VI e VIII; art. 174, $\S 3^{\circ}$; art. 200, VIII; art. 216, V; e especialmente o art. 225 e respectivos parágrafos), assim como às pessoas (art. 225, caput), é imposto um conjunto extenso de tarefas, o que atribui, atendendo à bilateralidade do fenômeno juridico, um direito subjetivo público a todos os cidadãos brasileiros, garantido pela ação popular (art. $5^{\circ}$ : LXXIII) e pela ação civil pública (art. 129, III). O desafio é, portanto, construir os meios idôneos para a realização eficiente e eficaz desse conjunto de tarefas, que encerra em si uma teleologia político-ambiental: estão fora de questão o juizo do custo-benefício e os critérios meramente alocativos.

Como diz Eros Roberto Grau, a defesa ambiental está diretamente relacionada com o desenvolvimento nacional, pois este se lastreia em uma economia

FAIIRE, Michael G. Environmental regulation. 1998. p. 443-520. Disponivel em: - http: /encyclo.findlaw.com;2300book.pd $>$. Acesso em: 14 abr. 2005.

FERNANDEZ. Maria Elizabeth Moreira. Direiı uo ambiente e propriedade privada - aproximação ao estudo da estrutura e das consequências das "leis-reserva" portadoras de vinculos ambientais. Coimbra: Coimbra. 2001. p. 09. 
auto-sustentada e suficientemente equilibrada. ${ }^{36}$ Nesse sentido apenas aparentemente a Constituição, de 1988, veio acirrar o xeque entre desenvolvimento econômico e ecologia ${ }^{37}$ pois capta a expressão "desenvolvimento" em um sentido muito mais amplo do que o mero crescimento econômico. O desenvolvimento sustentável é, assim, um objetivo fundamental de toda e qualquer atuação do Estado (art. 225 da Constituição de 1988); por isso a regulação econômica tem, de certa forma, de caminhar junto com a regulação ambiental.

\subsection{A chamada "tragédia do acesso livre"}

O problema fundamental da regulação ambiental é prevenir o sobreuso e o abuso dos bens ambientais, ${ }^{38}$ tais como o ar puro, a água, a fertilidade e a consistência dos solos, a fauna e a flora, a biodiversidade. Para tanto, é imprescindivel controlar o acesso e o uso, e, para esse controle, o ordenamento jurídico fornece um instrumento poderosíssimu, qual seja, o direito de propriedade.

A noção de direito de propriedade empregada neste estudo não é aquela restrita do direito civil tradicional, referente a um direito real sobre bens corpóreos (coisas). F. Comparato, há anos, tem observado a força expansiva do conceito de propriedade. ${ }^{3 y}$ É que a própria expressão "propriedade", a significar tudo aquilo que nos é próprio, refere-se a direito subjetivo patrimonial, independentemente de se créditos ou direitos reais. Trata-se, sem dúvida, de uma perspectiva mais realista, ${ }^{40}$ que observa que o direito de propriedade é o marco jurídico para a atribuição de bens, materiais ou imateriais, e a distribuição da riqueza, mediante a concentração de poderes em torno de um único titular, a quem é lícito tomar as mais diversas decisões a respeito da sorte do

36 GRAU, Eros Roberto. A ordem econômica na Constituição de 1988 - interpretação e crítica. 7. ed. São Paulo: Malheiros, 2002. p. 282.

37 Cf. NUSDEO, Fábio. Desenvolvimento econômico - um retrospecto c algumas perspectivas. In: SALOMÃO FILHO, Calixto (coord.). Regulaçào e desenvol'imento. São Paulo: Malheiros, 2002. p. 20.

is COLE, Daniel. Pollution and property - comparing ownership institutions for environmental protection. Cambridge: Cambridge, 2002. p. ix. É importante, nesse pontu, ressaltar outra diferença da regulação econômica para com a regulação ambiental. Para os autores como (SALOMÃO FII.HO. Calixıo. Regulação da atividade econômica - principios e fundamentos jurídicos. São Paulo: Malheiros, 2001. p. 26-70) que vêem na concorrência a finalidade da regulação econômica, certamente haverá de discrepar desta, em algum ponto, a regulação ambiental. pois nesta última o objetivo é restringir o acesso e não ampliá-lo.

is COMPARADU, rábio Konder. Estado, empresa e função sucial. Revisıa dos Tribunais, v. 732, p. 43-4, 1996.

*Veja-se que inclusive A. Menezes Cordeiro, quem é realmente um autor mais tradicional, afirma que "propriedade" maduz, conjuntamente com a livre iniciativa, o âmbito privado econômico do indivíduo face ao Estado (CORDEIRO, Antonio Manuel da Rocha e Menezes. Direilos reais. Lisboa: LFX, 1979. p. 13). 
bem de que é proprietário, além de determinar sua zona de privacidade com exclusão de todos os demais indivíduos. ${ }^{41}$

É neste sentido que G. Hardin observa que a degradação de bens ambientais e a poluição decorrem, em boa parte das vezes, dos estímulos gerados pelo acesso livre aos bens ambientais, isto é, pela situação de ausência do direito de propriedade desses bens, porque ninguém pode excluir o uso deles por parte de todos os indivíduos. ${ }^{42}$ Com efeito, historicamente tem sido comprovado que a res nullius, assim como outros bens objetos de direitos de propriedade incompletos, inconsistentes ou mesmo inefetivos sofreram abusos. No Brasil é sintomática a situação dos inúmeros terrenos no Vale do Paraíba. outrora ocupados pela Mata Atlântica devastada para a plantação do café e para as pastagens: em virtude de o título de propriedade nunca se ter apresentado suficientemente transparente, não era nem um pouco vantajoso recuperar os terrenos exauridos pelas plantações, senão ocupá-los com gado e assumir a posse de outros terrenos, para prosseguir com a cafeicultura, derrubando a floresta.

Dai sugerirem-se duas soluções para os problemas ambientais: definir direitos de propriedade privada sobre os bens ambientais, privatizando-os, ou controlar o acesso e o uso dos bens ambientais mediante a regulação ambiental. ${ }^{43}$ Mas como argutamente observou D. Cole, a regulação ambiental também implica a definição de direito de propriedade, na medida em que o Estado torna-se o titular dos bens ambientais, mediante a instituição da propriedade pública. ${ }^{14}$ Ainda quando a transferência do bem ambiental do patrimônio particular ao patrimônio público não se opere em termos formalmente jurídicos, é certo que a decisão de regular - por meio de multas, proibições, controles, imposições, direitos de poluir transferíveis etc. - determina a atribuição de deveres ao poluidor, caracterizando um modelo misto de propriedade. Nesse sentido, enquanto a privatização converte a não propriedade em propriedade privada individual ou comum, a regulação ambiental converte a não-propriedade em propriedade pública ou em modelos mistos público-privados de propriedade. ${ }^{45}$ A questão não é, portanto, a existência ou a não existência de direitos de propriedade, mas sim o tipo de propriedade sobre um determinado bem ambiental.

Ainda nesse sentido, os vários instrumentos regulatórios apontados por $\mathrm{R}$. Purcival et al. a saber: padronização, especificação de tecnologia, limites de emissões,

4 COOTER. Robert; ULEN, Thomas. Law and economics. Tradução Eduardo Suárez. Derecho y economía. México: Fondo de Cultura Económica, 1998. p.100-104.

\$2 HARUIN, G. The tragedy of the commons. Science, v. 162, p.1.244, 1968.

43 COLE. Daniel. New forms of private property: property rights in environmental goods. 1999. p. 275.

4 . Pollution and properly - comparing ownership institutions for environmental protection. Cambridge: Cambridge, 2002. p. 07.

s5 Id. Ibid., p. 08. 
advertências, limitações de uso, direitos transferiveis, multas, subsídios, depósitos forçados, responsabilizações, seguros obrigatórios, demonstração de planos e orçamentos, transparência, entre outros ${ }^{40}$ pressupõem, sem exceção, direito de propriedade, na medida em que estabelecem direitos e deveres a respeito de determinado bem ambiental que é atribuído a alguém. ${ }^{47}$

No Brasil, como será pormenorizado adiante, os mecanismos de proteção ambiental também são todos baseados no direito de propriedade. O problema então é saber qual modelo de propriedade deve ser utilizado em determinadas circunstâncias.

\subsection{Tipologia da propriedade quanto à pessoa do titular}

No Brasil, o direito de propriedade é necessariamente atribuído a uma pessoa, física ou jurídica. Não há direito de propriedade transindividual em nosso país.

Assim, há a propriedade privada, que é o direito subjetivo atribuído a uma pessoa jurídica de Direito Privado ou a uma pessoa jurídica de direito público sujeita a regime de direito privado, tal qual ocorre com a propriedade dos bens dominicais (art. 99, parágrafo único do Código Civil). Mesmo neste caso, contudo, a simples presença do Estado, independentemente de exercer imperium, já determina um regime sui generis. ${ }^{48}$ No Direito Privado de propriedade, o respectivo titular tem a faculdade de usar e os poderes formativos de fruir e dispor do bem, conforme sua função social (art. 1.228 do Código Civil e respectivos parágrafos ${ }^{49}$ ). $\mathrm{O}$ sujeito passivo universal correspectivo tem 0 dever comportamental de não-interferir no exercício dos poderes e faculdades do proprietário; e tem a pretensão ao exercício do direito conforme sua função social.

A propriedade privada pode ser individual ou comum, também chamada, neste último caso, coletiva. É a hipótese do condomínio (arts. 1.314 e seguintes do Código Civil), que apresenta variações nas quais o aspecto da comunhão mais ou menos se sobressai. A figura típica da propriedade privada é a propriedade individual, tal qual exposta acima. A propriedade privada comum tem a característica de ter como titular

46 PERCIVAL, R. et al. Environmental regulation - law, science and policy. Boston: Little Brown, 1996. p. 1548 .

17 COLE, Daniel. Pollution and property - comparing ownership institutions for environmental protection. Cambridge: Cambridge, 2002. p. 14.

48 Veja-se, dessarte, que os bens públicos, mesmo os dominicais, não estão sujeitos à usucapião, conforme o art. 102 do Código Civil.

49 Destaque-se o $\S 1$ " do art. 1.228: "O direito de propriedade deve ser exercido em consonância com a suas funalidades econômicas e sociais e de modo que sejam preservados, de conformidade com o estabelecido em lei especial. a flora, a fauna,as belezas naturais, o equilibrio ecológico e o patrimônio histórico e artístico, bem como evitada a poluição do ar e das águas" 
uma pluralidade definida de particulares, os quais não podem se excluir do uso do bem objeto da propriedade, mas podem excluir os demais indivíduos não-titulares.

E há, enfim, a propriedade pública, direito subjetivo atribuido a uma pessoa jurídica de Direito Público sujeita a um regime de Direito Público. Nesse caso, há a propriedade de bens de uso comum (próxima à idéia de direito transindividual de propriedade) e a propriedade de bens de uso especial (art. 99, l e II do Código Civil). No fundo, o controle dos bens objetos do direito público de propriedade cabe aos burocratas e aos agentes políticos, os quais definem e exercem a regulação ambiental e, portanto, fixam o acesso e o uso daqueles bens. ${ }^{40}$

Esses três tipos de direitos de propriedade - propriedade privada individual, propriedade privada comum, propriedade pública - são meramente modelos de análise. É extremamente difícil verificar tipos puros em um determinado ordenamento jurídico concretamente considerado. As mais das vezes o que se observa é a misturação desses tipos. admitindo modelos mistos de propriedade. Isso é particularmente corriqueiro em sede de regulação ambiental, na qual, aliás, se impõe a decisão de qual dos tipos deve ser adotado em uma certa circunstância: até que ponto deve o Estado atribuir-se propriedade pública em vez de atribuir propriedade privada, limitada ou ilimitada, aos particulares ou a certos grupos de particulares?

Não há. com efeito, um único tipo de propriedade que seja sempre a melhor solução, independentemente dos padrões institucionais, tecnológicos e até mesmo ecológicos. Como diz D. Cole, cada circunstância exige uma comparação dos custos de produção, exclusão e administração. Assim, a propriedade privada individual pode ser adequada nos casos em que os custos de administração interna sejam muito altos, mas os custos de exclusão sejam muito baixos. Já a propriedade privada comum ou a propriedade pública pode ser adequada na situação inversa: quando os custos de exclusão forem altos, mas os de administração, baixos. Por fim, quando os custos tanto de exclusão quanto de administração interna forem muito altos, o acesso livre talvez seja inevitável. " Por conseguinte, o melhor tipo de propriedade é aquele que, sob certas circunstâncias, alcance os objetivos regulatórios com o menor custo, calculado com base na soma dos custos de cumprimento, de administração e de poluição ou consumo residuais. $^{52}$

« COLE, Daniel. Pollution and property - comparing ownership institutions for environmental protection. Cambridge: Cambridge, 2002. p. 08. Cabe, aqui, reproduzir a ilustraçâo proposta pelo autor, para representar graficamente os tipos de propriedade, adaptando, porém ao direito positivo brasilciro (p. 10).

st Id. Ibid., p. 17.

$\therefore$ Id. lbid. 


\section{Os tipos de propriedade como mecanismos regulatórios}

\subsection{Propriedade pública}

É tendência, no Brasil, atribuir os bens ambientais ao patrimônio das pessoas jurídicas de direito público. A Constituição da República, por exemplo, atribui à União os recursos naturais da plataforma continental (art. 20, V) e aos Estados residualmente as águas (art. 26, I). Os ecossistemas da Floresta Amazônica. da Mata Atlântica. da Serra do Mar. do Pantanal Mato-Grossense e da Zona Costeira são atribuidos, também pela Constituição da República, ao "patrimônio nacional" (art. 225, § $4^{\circ}$ ) genericamente. O Supremo Tribunal Federal e o Superior Tribunal de Justiça entendem, se bem que implicitamente, que a propriedade, neste caso, é da União; ${ }^{53}$ de qualquer forma, o caráter de propriedade pública é inqüestionável. Trata-se. em última análise, de estatização dos bens ambientais. que é, aliás. uma modalidade de regulação. ${ }^{54}$

Ainda no campo da regulação ambiental, é possível que não haja uma atribuição direta de propriedade pública, mas a intervenção estatal nos bens ambientais acaba por transferir, de fato, direitos de propriedade para o Estado. Trata-se de uma propriedade pública implicita, a qual tem lugar a fim de transferir ao Estado poderes suficientes para atingir as finalidades regulatórias. Geralmente, a regulação ambiental estabelece modelos mistos de propriedade, os quais compreendem tanto direitos de propriedade privada quanto direitos de propriedade pública sobre bens ambientais. Ocorre por vezes, no entanto, que a regulação pode ser tão ampla que implicitamente ocorra a atribuição de propriedade pública, burlando as regras sobre desapropriação por interesse social ${ }^{55}$ (art. $2^{\circ}$, VII da Lei 4.132/62). De qualquer maneira, vale observar que a desapropriação. com o fim de proteção ambiental. fundamenta-se menos no interesse social do que no interesse econômico-privado de determinado particular. ${ }^{56}$

Com efeito, quando a regulação ambiental começa a tomar corpo nos anos 1970. compreendendo a qualidade ambiental como um fím em si mesma e não meramente como um meio hábil para a promoção da saúde humana ou para a utilização econômica de certos recursos, a propriedade pública surge como um paradigma não apenas como direito de crédito a uma indenização por dano ambiental. mas sobretudo como um instrumento regulatório em si mesma, conferindo ao Estado poderes

\footnotetext{
53 Cf. Revisıa Trimestral de Jurisprudência 164/158 e Sümula 91 do STJ.

s BREYER, S. Regulation and its reform. Cambridge: Harvard I/niversity, 1982. p. 181-3.

5s FERNANDEZ, Maria Elizabeth Moreira. Direito ao ambiente $\epsilon$ propriedade privada aproximação ao estudo da estrutura e das conseqüências das "leis-reserva" portadoras de vinculos ambientais. Coimbra: C'oimbra, 2001. p. 223-4.

s6 Id. Ibid., p. 10.
} 
diretamente sobre os bens ambientais. A crença no Estado-providência, segundo a qual o poder público tinha a obrigação de fornecer certos bens, no caso ambientais. os quais o mercado não poderia proporcionar, levou às formas clássicas de regulação ambiental. baseadas no exercício do poder de polícia administrativo.

Os empresários produtores de mercadorias que impunham riscos aos bens ambientais, tais como os agrotóxicos, passaram a ter suas atividades reguladas a ponto de o Estado determinar as etapas do processo produtivo, especialmente no momento das embalagens dos produtos (Lei n. 7.802/89). Dessa forma, quando o Estado determina uma série de deveres aos particulares, atribui a si mesmo direitos de propriedade. tanto que o descumprimento deles resolver-se-á em indenizações. ${ }^{57}$

As justificativas para a propriedade pública se baseiam, invariavelmente. em razões de economia de escala e custos insuportáveis para atribuição de direitos privados. Em muitas circunstâncias, a propriedade pública dos bens ambientais pode ser preferível à propriedade privada, tanto do ponto de vista econômico quanto ecológico.

Basta pensar no caso brasileiro. em que os ecossistemas ainda existentes conferem ao país o status do território com a maior biodiversidade de espécies de plantas e animais do mundo. ${ }^{58} \mathrm{O}$ tamanho dos terrenos visando à manutenção dessa diversidade biológica tem proporções continentais, como dá exemplo a Amazônia. Ora. seria extremamente custoso. do ponto de vista econômico. outorgar a Amazônia aos particulares. na medida em que, conforme a demonstração de D. Lueck, os custos de negociação são diretamente proporcionais ao tamanho do terreno necessário para preservar a flora e a fauna ${ }^{59}$ e ainda mais a biodiversidade. Como será visto a seguir, também do ponto de vista ambiental a propriedade privada seria desaconselhável nesse caso.

\subsection{Propriedade privada}

$\mathrm{Na}$ marola das desregulações/privatizações, as críticas à propriedade pública dos bens ambientais seguem, invariavelmente, o mesmo ritmo daquelas dirigidas à presença do Estado-empresário. A atribuição explícita de propriedade pública dos bens ambientais é entendida como perniciosa, porque ao contrário dos proprietários privados, os burocratas e os políticos que administram recursos públicos, inclusive ambientais, não são movidos por motivações lucrativas para maximizar o valor econômico líquido dos

57 COLE, Daniel. Pollution and properry - comparing ownership institutions for environmental protection. Cambridge: Cambridge, 2002. p. 37.

58 SANTILLI, J. Socioambientalismo $\epsilon$ novos direitos - proteção jurídica à diversidade biológica e cultural. São Paulo: Peirópolis, 2005. p. 104.

s9 LUECK, Dean. The economic nature of the wildlife law. Journal of Legal Studies, n. 18, p. 302-9, 1989. 
bens sob seu controle. ${ }^{61}$ Como D. Cole aponta, isso não é um problema muito sério para a proteção ambiental, além de se basear em uma premissa equivocada: a de que os particulares não levariam os bens ambientais à destruição exclusivamente por serem proprietários deles. ${ }^{01} \mathrm{Na}$ crítica de D. Bromley, do ponto de vista econômico é racional exterminar em vez de conservar certos bens ambientais. ${ }^{62} \mathrm{O}$ caso das madeireiras no Brasil é sintomático dessa realidade: o extermínio de uma floresta ou de uma espécie de árvore pode ser interessante para o respectivo proprietário quando a taxa de desconto excede o máximo potencial reprodutivo dessas espécies e um lucro imediato pode ser obtido dizimando todas as árvores. O mesmo vale para as espécies animais.

De qualquer forma, o movimento "ambientalista de livre mercado" (freemarket environmentalism) postula a privatização dos bens ambientais, isto é, a transferência completa da propriedade pública para a propriedade privada. Mesmo os direitos de propriedade pública implícitos geram sérias ineficiências. em virtude do excesso de licenças, imposições e proibições. ${ }^{63}$

As experiências de privatizações de bens ambientais verificadas foram, contudo, desastrosas. Em Botswana, as pastagens foram privatizadas visando à redução da superexploração; todavia us resultados foram piores do que o status quo ante, na medida em que os proprietários trataram de adquirir o gado dos camponeses excluídos do acesso à terra, fato que diminuiu drasticamente o preço dos animais, e continuaram superlotando as pastagens. ${ }^{64}$ No Reino Unido, o fato histórico da privatização das florestas no século XIX teve como resultado a sua destruição quase completa.

A crítica à propriedade pública também caminha no sentido de que as empresas públicas que geram riscos ambientais tenderiam a ser afastadas da regulação ambiental se o controle dos bens prejudicados fosse exclusivo do próprio Estado. Haveria tendência de insulamento. ${ }^{65}$ Com essa base argumentativa. fica claro que o ambientalismo de livre mercado se sustenta na crítica não exatamente à propriedade pública, mas sim à administração múltipla dos bens econômicos: o Estado, na sua função de regulador ambiental, buscando a proteção ambiental, e de regulador econômico, buscando o crescimento econômico, lida com um conflito intrínseco de interesses. Mas isso deve ser resolvido no campo da própria regulação ambiental, que deve conformar a

60 POSNER, Richard. Economic analysis of law. Boston: Little Brown. 1992. p. 84.

61 COLE, Daniel. Pollution and property - comparing ownership institutions for environmental protection. Cambridge: Cambridge, 2002. p. 39.

62 BROMLEY, D. Environment and economy: property rights and public policy. Oxford: Blackwell, 1991. p. 171.

63 Cf. a exposição de COLE, Daniel. Pollution and property - comparing ownership institutions for environmental protection. Cambridge: Cambridge, 2002.p. 86-7.

Id. Ibid., p. 97.

65 Cf. Id. Ibid., p. 105. 
regulação econômica. No Brasil isso decorre de imposição constitucional (art. 225). A unidade de regulação pode ser obtida pelo Estado. Diversamente, a propriedade privada, se promove unidade de administração dos bens ambientais, não é capaz de sujeitá-los ao interesse público à sua efetiva proteção. A ênfase está, portanto, em cuidar, no âmbito do Estado, da unidade da atividade regulatória. ${ }^{66}$

\subsection{Modelos mistos}

Os modelos mistos de propriedade aparecem em duas perspectivas. A primeira se refere à predominância da propriedade pública dos bens ambientais ou ao controle acentuado deles. Nesse caso, o Estado pode estabelecer limites à poluição e, ao mesmo tempo, direitos ou permissões de uso dos bens dentro desses limites. Aos particulares são atribuídos, assim, direitos sobre esses bens de duas formas: ou permissões de poluição, transferiveis ou-não, ou concessões. Já a segunda se refere a uma situação inversa: a publicização parcial de bens ambientais atribuídos a particulares ocorre na servidão administrativa e nos tombamentos. ${ }^{67}$

A teoria dos direitos de propriedade para poluir tomaram corpo na década de 70 e atualmente são o paradigma do Protocolo de Kyoto. Até então, a regulação ambiental se dava predominantemente de acordo com o segundo marco regulatório, baseado no poder de polícia da Administração: o regulador estabelecia objetivos ambientais e padrões industriais, sanitários e tecnológicos para serem observados. Nos Estados Unidos, o Clean Air Act contemplou, pela primeira vez o sistema de direitos negociáveis de poluir.

J. Dales foi um dos principais economistas que criaram a teoria dos direitos de poluir transferiveis. A idéia era realocar direitos de propriedade sobre o ar atmosférico, limitados, mas transferíveis, como uma alternativa menos custosa à clássica regulação ambiental, presa ao exercício do poder de polícia. Assim, privatizando alguns direitos de propriedade sobre certos bens ambientais, o Estado estaria permitindo que o mercado diminuísse os custos para atingir as reduções na poluição e alcançar outros objetivos de proteção ambiental.

A vantagem desse sistema é que ele leva em consideração as diferenças estruturais de custos que cada empresa tem para controlar a poluição. O controle administrativo freqüentemente faz tábula rasa de diferentes custos para o cumprimento das metas regulatórias, torçando todas as empresas, independentemente de suas

${ }_{66}$ COLE, Danicl. Pollution and property - comparing ownership institutions for environmental protection. Cambridge: Cambridge, 2002. p. 107.

67 Id. Ibid.. p. 46. 
características, a reduzir emissões segundo um mesmo padrão e um mesmo limite. $O$ sistema de direitos de propriedade privada sobre o ar levaria, por outro lado. à alocação da maior parte da redução de poluição àquelas empresas com menores custos de controle. As empresas que não podem reduzir emissões de forma tão barata podem poluir mais, mas terão de pagar pelo privilégio adquirindo direito de propriedade dos vendedores - aqueles que controlam a um custo menor - em um mercado livre. $\mathrm{O}$ propósito primário de permitir o comércio é, portanto, não a redução de emissões, mas a diminuição de custos de reduzir as emissões. ${ }^{68}$

Para esse sistema, é fundamental que a agência reguladora - que no Brasil é o IBAMA - detenha tecnologia e aparato técnico suficientemente sofisticados para desenvolver o programa ${ }^{69}$ Nosso ordenamento jurídico não prevê nada parecido, mas a experiência estadunidense da EPA (Environmental Protection Agency) registra quatro esquemas regulatórios ${ }^{70}$ com base nos direitos de propriedade de poluir negociáveis: netting, ${ }^{71}$ offsets, ${ }^{72}$ bubbles $^{73}$ e banking. ${ }^{74}$

No fundo, esse sistema ficou bem abaixo das expectativas bem como do necessário para manter o equilibrio ecológico -- porque não chegou a se constituir em uma autêntica regulação ambiental: seus objetivos foram, exclusivamente, diminuir os custos empresariais para alcançar as metas regulatórias, e não a proteção dos bens ambientais.

\subsection{Comunhão de direitos e crítica do condomínio tradicional}

As experiências mais bem-sucedidas de proteção ambiental. assim entendidas aquelas em que não ocorreu depredação de bens ambientais por seu sobreuso durante um período mais ou menos longo de tempo, encontram-se na propriedade privada dos bens ambientais, só que atribuída a uma pluralidade de sujeitos. É uma espécie de condomínio, na qual o aspecto da comunhão se ressalta. Designa-se, portanto,

68 COLE, Danicl. Pollution and property - comparing ow nership institutions for environmental protection. Cambridge: Cambridge. 2002. p. 46-7.

69. Id. Ibid., p. 58.

79 COLE, Daniel. New forms of private property: property rights in environmental goods. 1999, p. 285-89. Disponível em: http:i/encyclo.findlaw.com/1910book.pdf . Acesso em: 14 abr. 2005.

7 Trata-se de uma forma de desconto: as emissões adicionais de uma nova fonte são descontadas das diminuições ocorridas de uma outra fonte.

72 Trata-se de uma forma de compensação: as fábricas podem se reinstalar em outras regiões que estejam abaixo do limite permitido de emissōes.

${ }^{3}$ Trata-se de um reservatório das emissões: em vez de jogar tudo de uma vez no ambiente. a empresa armazena poluição e vai eliminando aos poucos, para não ultrapassar os limites.

7 Trata-se de um banco de créditos de emissão: a empresa que lica abaixo dos limites de poluição pode acumular créditos para futuramente usar, vender ou mesmo alugar. 
como propriedade coletiva ou propriedade comum, isto é, a propriedade atribuída a um grupo de particulares, quem a exerce com exclusividade em relação aos indivíduos nãotitulares, e em comunhão entre si, de forma que os titulares não podem excluir-se uns aos outros, competindo a todos regular em comum o acesso e o uso do bem ambiental.

A propriedade comum foi observada por cerca de mil anos no Norte da Europa e hoje ela ocorre sobre as terras cultiváveis nos Andes peruanos e bolivianos, sobre as Iriach $^{75}$ japonesas e sobre os lagos pesqueiros turcos. ${ }^{70}$ Israel registra experiências muito semelhantes nos kibutz.

No Brasil. há experiências interessantes de propriedade comum, apesar de - e nisto está o enorme problema - o instituto não ser reconhecido pelo direito posto. Em nosso País, a pluralidade de sujeitos. proprietária de um bem, está submetida à disciplina do condomínio tradicional do Código Civil (arts. 1.314 e seguintes). Nesse regramento, a pluralidade de sujeitos é tratada como uma situação anômala e efềmera, pois a teleologia é destinar o bem a um único titular. facilitando a extinção do condomínio, por um lado, e não limitando o exercício dos direitos de cada condômino, por outro. ${ }^{77} \mathrm{~A}$ comunhão que se estabelece é simples e segundo quotas (Bruchteilegemeinschafi).

Veja-se, assim. que as experiências brasileiras referem-se às aldeias indígenas. aos quilombos e outras comunidades locais que desenvolveram, ao longo de anos. sistemas sustentáveis de exploração dos recursos naturais. ${ }^{78}$ Mas em nenhuma delas existe titulo legal de propriedade comum: as terras indígenas são de propriedade pública da União (art. 20. XI da Constituição da República); a população quilombola, apesar de ter direito de propriedade privada assegurado pelo Ato das Disposições Constitucionais Transitórias (art. 68), até hoje não tiveram suas terras demarcadas e padecem de um problema jurídico para garantir a efetividade de seus direitos: as comunidades locais não são sequer reconhecidas por texto legislativo.

O ordenamento juridico brasileiro apresenta-se, assim, equivocado ao privilegiar o modelo romanístico de propriedade comum, e a regulação ambiental tende a sofrer imensamente com isso. É premente a criação de uma propriedade comum, na qual os condôminos sejam efetivamente comunheiros em mão comum (Gemeinschaft zur gesamten hand): neste modelo - como ocorre com a herança, a sociedade em comum e a comunhão matrimonial - o proprietário é a pluralidade de sujeitos como um todo, e não cada um dos sujeitos individualmente considerados. O que significa que o bem do qual a

75 As Iriachi são terras aráveis de vilarejos situados em montanhas.

76 COLE, Daniel. Pollution and property - comparing ownership institutions for environmental protection. Cambridge: Cambridge. 2002. p. 112-20.

77 BESSONE, D. Direitos reais. 2. ed. São Paulo: Saraiva, 1996. p. 79-87.

78 Cf. SANTILLI, J. Socioambientalismo e novos direitos - proteção juridica à diversidade biologica e cultural. São Paulo: Peirópolis, 2005. p. 103-81. 
pluralidade seja titular tem de ser administrado em comum e não por cada indivíduo comunheiro: o consenso e a participação se impõem.

É fundamental que se estabeleça, portanto, o instituto da propriedade comum e, visando finalidades da regulação ambiental, outros requisitos devem ser observados para a efetividade de tal instrumento regulatório - o mais, repita-se, bemsucedido. Destarte, é necessário que se estabeleçam com clareza as fronteiras da propriedade comum, bem como seu conteúdo e a respectiva extensão; que se fixem regras apropriadas para cada tipo de bem ambiental a ser atribuído como propriedade comum, considerando-se ainda a região em que ele se encontra; que se outorgue poder de decisão aos comunheiros; e que se implantem formas de resolução de controvérsias de baixo custo ${ }^{79}$

As razões do sucesso da propriedade comum referem-se à resolução do problema do acesso livre, pois o bem ambiental é realmente atribuído a alguém - no caso, um grupo de pessoas - e há unidade de administração, pois os membros autolimitam o exercício de seus direitos, com base em uma decisão consensual.

\section{Conclusão}

Sem dúvida, a regulação ambiental tem como pressuposto a atribuição de direitos de propriedade, compreendida esta expressão em seu sentido amplo de controle patrimonial das riquezas econômicas com exclusividade. Os modos com que são atribuídos os direitos de propriedade variam de acordo com os objetivos da regulação ambiental, mas, em todo caso, o tipo de propriedade que até hoje se mostrou mais bemsucedido para proteger os bens ambientais, sem exclusão do ser humano, é a propriedade privada comum, a qual não é reconhecida pelo ordenamento jurídico brasileiro.

Os direitos privados de propriedade e os modelos mistos de propriedade que implicam uma parcial privatização dos bens ambientais, tais como a concessão e o sistema de comercialização de direitos de poluir. são historicamente concebidos mais como forma de regulação econômica do que de regulação ambiental, pois seu objetivo é aumentar a eficiência dos empresários e não tanto lograr a efetiva proteção dos bens ambientais.

A propriedade pública revela-se, na maior parte das vezes, um tipo de propriedade adequada para a proteção ambiental, mas há sérios problemas com sua efetividade, na medida em que nem sempre o Estado tem a posse direta dos bens ambientais - o que demandaria custos exorbitantes.

7 COLE, Daniel. Pollution and property - comparing ownership institutions for environmental protection. Cambridge: Cambridge, 2002. p. 122. 
A propriedade privada comum apresenta bons resultados, na medida em que impede materialmente o acesso livre, e a presença de uma pluralidade de sujeitos permite uma autoregulação das atividades que exploram o bem ambiental, impedindo seu sobreuso e abuso. O que está na agenda da regulação ambiental brasileira é, assim. reconhecer a propriedade comum e expandi-la às comunidades locais, logrando a compatibilização de sistemas de exploração dos recursos naturais com 0 desenvolvimento sustentável.

São Paulo, setembro de 2006.

\section{Referências}

ACUTT, Melinda; Elliott, Caroline. Regulatory conflict? Environmental and economic regulation of electricity generation, 1998, pp. 1-24. Disponivel em: <http://papers.ssm.com/sol3/papers.cfm? abstract_id=200572>. Acesso em: 14 abr. 2005.

ARANTES, Paulo Eduardo. A viagem redonda do capitalismo de acesso. Opinião, n. 58, p. 42-3, 2004.

BESSONE, Darcy. Direitos reais. 2. ed. São Paulo: Saraiva, 1996.

BREYER, Stephen. Regulation and its reform. Cambridge: Harvard University, 1982.

BROMLEY, Daniel W. Environment and economy: property rights and public policy. Oxford: Blackwell, 1991.

COASE, Ronald Harry. The firm, the market and the law. Chicago: University of Chicago, 1990.

CORDEIRO. Antonio Manuel da Rocha e Menezes. Direitos reais. Lisboa: LEX. 1979.

COLE, Daniel H. New forms of private property: property rights in environmental goods, 1999. p. 274-314. Disponivel em: <http://encyclo.findlaw.com/1910book.pdf>. Acesso em: 14 abr. 2005.

Pollution and property - comparing ownership institutions for environmental protection. Cambridge: Cambridge, 2002.

COMPARATO, Fábio Konder. A afirmação histórica dos direitos humanos. 2. ed. São Paulo: Saraiva, 2001.

. Estado, empresa e função social. Revista dos Tribunais, v. 732, p. 38-46, 1996.

COOTER, Robert: Ulen. Thomas. Law und economics. Tradução Suárez. Eduardo L. Derecho y economía. México: Fondo de Cultura Económica. 1998. 
FAURE, Michael G. Environmental regulation. 1998. p. 443-520. Disponível em: $<$ http://encyclo.findlaw.com/2300book.pdf>.Acesso em: 14 abr. 2005.

FAURE, Michael: Skogh, Göran. The economic analysis of environmental policy and law - an introduction. Cheltenham: Edward Elgar, 2003.

FERNANDEZ, Maria Elizabeth Moreira. Direito ao ambiente e propriedade privada aproximação ao estudo da estrutura e das conseqüìncias das "leis-reserva" portadoras de vinculos ambientais. Coimbra: Coimbra, 2001.

FINDLEY, Roger W.; Farber, Daniel A. Environmental law. 5. ed. St. Paul: West, 2000.

GALBRAITH. John Kenneth. Uma teoria do controle de preços a exposição clássica. Tradução de José Murilo de Carvalho. A theory of price control - the classic account. Rio de Janeiro: Forense, 1986.

GRAU, Eros Roberto. A ordem econômica na Constituição de 1988 - interpretação e crítica. 7. ed. São Paulo: Malheiros, 2002.

O direito posto e o direito pressuposto. 3. ed. São Paulo: Malheiros, 2000.

GROSSI, Paolo. Mitologias juridicas da modernidade., 2001. Tradução Amo Dal Ri Júnior. Mitologie giuridiche della modernità. Florianópolis: Fundação Boiteux, 2004.

HARDIN, Garrett. The tragedy of the commons. Science, v. 162, p. 1.243-1.248, 1968.

HAYEK, Friedrich August von. Individualism and economic order. Chicago: University of Chicago, 1948.

KLLSEN, Hans. Reine Rechtslehre. 1960. Tradução Mario G. Losano. La dottrina pura del diritto. Turim: Einaudi, 1990.

LUECK, Dean. The economic nature of the wildlife law. Journal of Legal Studies, n. 18, p. 291 $324,1989$.

MACHADO, Paulo Affonso Leme. Direito umbiental brasileiro. 10. ed. São Paulo: Malheiros. 2002.

MATTOS, Paulo et al. Regulação econômica e democracia - o debate norte-americano. São Paulo, $34,2004$.

MELlo, Celso Antonio Bandeira de. Curso de direito administrativo. 14. ed. São Paulo: Malheiros. 2002. 
PEREIRA, Luiz Carlos Bresser. Reforma do Estado para a cidadania - a reforma gerencial brasileira na perspcctiva internacional. São Paulo: 34, 1998.

PERCIVAL, Robert; Miller, Alan S.: Schroeder, Christopher H. Environmental regulation - law, science and policy. Boston: Little Brown, 1996.

POLANYI, Karl. The great transformation. Nova Yorque: Farrar and Rinehart, 1944.

POSNER, Richard A. Economic analysis of law: Boston: Little Brown, 1992.

RIVLIN, Gary. Energia "limpa" atrai investimentos nos EUA. Folha de S. Paulo, B12, 29.06.2005.

SALOMÃO FILHO. Calixto. Regulação da atividade econômica - princípios e fundamentos jurídicos. São Paulo: Malheiros. 2001.

SALOMÃO FILHO, Calixto (Coord.). Regulação e desenvolvimento. São Paulo: Malheiros, 2002.

SANTILlI, Juliana. Socioambienalismo e novos direitos - proteção jurídica à diversidade biológica e cultural. São Paulo: Peirópolis, 2005.

SAVATIER, René. Du droit civil au droit public a travers les personnes, les biens et la responsabilitè civile. Paris: LGDJ, 1950.

SILVA, José Afonso da. Direito ambiental constitucional. 4. ed. São Paulo: Malheiros, 2002.

SOARES, Guido Fernando Silva. Direito internacional do meio ambientc emergência, obrigações e responsabilidades. 2. ed. São Paulo: Atlas, 2003. 